imminent second coming were the endeavours of Europe's peoples, the English included, to frustrate the absolutist tendencies of their rulers. ${ }^{249}$ 'This seems to be clear', he wrote, 'that their governments are generally so tyrannous and insupportable that, besides God's design, they do bespeak their own ruin. ${ }^{225}$ The civil war in England was for Juxon just one theatre in a European-wide conflict between the forces of AntiChrist and the 'despised generation' - a group which seems to have included not only the Protestant party but the oppressed peoples of Christendom in general.

\title{
Editorial decisions and practices
}

The main aim has been to provide a clear text of the journal with a view to making it as accessible as possible. Hence, abbreviations have been expanded and spelling, the use of capitals, punctuation and paragraph structure have generally been modernised. The major exceptions to this practice have been the retention of the original variant spellings of the word 'interest' as well as the latinised forms of some other words, and Juxon's deliberate use of the Scottish term 'twa' for 'two', where a particular significance is attached to the spelling. Translations have been provided in footnotes for passages in French or Latin in the text or appendices. The editors have also made insertions into the text enclosed within square brackets to help clarify the syntax or to provide essential information. Dates are in the 'old style' except that the new year it taken to begin on the I January. In order to ease chronological reference, dates given in the text are highlighted in bold type. Furthermore, footnotes are used to provide the precise dates of actions or events noted in the text and to correct faults in Juxon's own dating.

The notes and references to dates which Juxon periodically provides in the margins of the journal are distinguished from the rest of the text by being placed within angled brackets $<>$. Words crossed out, substituted or interlined in the journal are underlined and explained. Folio references to the original text are contained within square brackets. London is the place of publication of works cited in footnotes unless otherwise stated.

\footnotetext{
${ }^{249}$ Below, pp. 92, $13^{2 .}$

${ }^{25^{\circ}}$ Below, p. $9^{2}$.
} 